\title{
The effect of partial automation on the productivity and cost of a mobile tower yarder
}

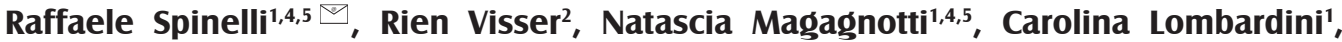 \\ Giovanna Ottaviani ${ }^{3}$
}

Spinelli R., Visser R., Magagnotti N., Lombardini C., Ottaviani G., 2020. The effect of partial automation on the productivity and cost of a mobile tower yarder. Ann. For. Res. 63(2): 3-14.

Abstract Integration of technology is commonplace in forestry equipment supporting higher levels of automation and efficiency. For technology adoption to be successful it must demonstrate improvement in productivity, cost-effectiveness or in human factors and ergonomics. Cable yarding lends itself to automation with repetitive machine movement along a fixed corridor, as established by the skyline. This study aimed at investigating the difference in productivity between the two possible settings (manual and automated) of a Valentini V850 yarder equipped with automatic path programming, with a Bergwald 3-t carriage and radio controlled chokers. The study took place in the northern Italian Alpine eastern region over a period of 8 days on two separate corridors, resulting in 280 measured cycles split between manual and automated. Results in terms of absolute numbers were very close for the two system options, but significant differences were found. For example, inhaul time was longer, but outhaul time shorter for the automated system. Productivity ranged from 8.2 to $13.3 \mathrm{~m}^{3} \mathrm{PMH}^{-1}$, and cost from approximately 20 to $30 € \mathrm{~m}^{-3}$. The automated system did achieve a significantly higher productivity, but differences declined with extraction distance. When that was combined with the slightly higher cost for the automated system, the automated system was more cost-effective on extraction distances less than $200 \mathrm{~m}$, and the manual system on longer distances.

Keywords: logging, efficiency, harvesting, operations

Addresses: ${ }^{1} \mathrm{CNR}$ Institute of Bioeconomy, Sesto Fiorentino, Italy $\mid{ }^{2} \mathrm{School}$ of Forestry University of Canterbury, Christchurch, New Zealand ${ }^{3}$ Norwegian Institute of Bioeconomy Research, Ås, Norway | ${ }^{4}$ AFORA - University of the Sunshine Coast, Maroochydore, QLD Australia | ${ }^{5}$ Skogforsk, Uppsala, Sweden œCorresponding author: Raffaele Spinelli (raffaele.spinelli@ibe.cnr.it).

Manuscript received May 13, 2020; revised November 6, 2020; accepted November 27, 2020. 


\section{Introduction}

Over the past decade, forest technology has made significant progress in order to support a dynamic industry that sets urgent demands for new equipment and techniques (Thor 2014, Müller et al. 2019). Within the specific field of forest operations, most new developments have aimed at increasing productivity and reducing labor input and risk exposure which have been the main objectives of forest mechanization for decades (Heinimann 2007). Improvements are continuously introduced to forestry machines and promoted by equipment manufacturers in their effort to increase market shares. Embedded electronics are now commonplace and can increase the complexity and accuracy of tasks undertaken, but they can also help automate specific functions and mitigate the consequences of operator fatigue. The data collected during harvesting can be integrated with geospatial information to optimize machine performance, leading to precision forestry (Mousazadeh 2013).

New technology such as intelligent boom control makes it easier for beginners to learn how to efficiently operate their machines and leads to achieving high productivity within a short learning time (Löfgren 2009, Manner et al. 2017). In fact, the idea of intelligent control systems dates back a few decades (Manninen et al. 1984, Guimier 1991), but it has become a commercial reality only in recent years, thanks to the development of low-cost sensor and computing solutions. As enabling technologies keep developing, so the automation of mechanized harvesting systems will increase, until robots will eventually appear (Thor 2014, Visser 2018). Already today, advanced automation concepts are available for specific tasks and machines, and there are examples of autonomous, unmanned forwarders and other ground-based forest machines (Hellström et al. 2009, Ringdahl et al. 2012, Parker et al. 2016). Automation is expected to bring additional benefits beyond increased productivity and reduced harvesting cost, and especially enhanced worker health and safety (Acemoglu \& Restrepo 2017). For instance, harvester operators experience a very high mental workload and they can quickly fatigue (Spinelli et al. 2020) and forwarder operators may spend lots of time driving over the same trails, which will lead to monotony and boredom (Grzywiński \& Hołota 2006). A higher degree of machine autonomy could mitigate operator workload and improve safety, health and general wellbeing - besides offering productivity gains that can be sustained in the long run (Cottrel \& Barton 2013, Visser \& Obi 2019).

The harsh forest environment may tax the limits and the reliability of all types of instruments. Besides, the great diversity encountered in forest environments makes it quite challenging to obtain reliable measurements of essential state parameters in real time, which imposes a strong limitation to developing autonomous machines (Billingsley et al. 2008). Similar challenges are faced with tele-operation, whereby the operator is removed from the machine and controls it from a safer and more comfortable work station (Milliken et al. 2015). Although apparently simpler than full autonomous operation, tele-operation requires efficient wireless communication, which can be a limiting factor in forestry environments, and in the countryside more in general (Prasad-Pant \& Hambly-Odame 2017). However, encouraging results have been obtained with autonomous or partiallyautonomous forwarders, where the driver teaches the route to the machine, which will then take over and repeat the same circuit over again, until the driver takes over and changes to a new route (Hellström et al. 2005).

That exemplifies two important things: first, autonomous or semi-autonomous operation is (obviously) easier with simple tasks, such as following a pre-defined route in low-traffic areas. That is why successful examples of commercial applications of autonomous 
vehicles are with industries such as mining (e.g., Scania 2020), and, second, that both scientific and commercial research is focusing on ground-based wheeled vehicles.

In contrast, less attention is devoted to other forms of transportation that may offer better conditions for automation. In forestry, cable yarding is the dominant wood extraction technology for those many sites that are too rugged for ground-based equipment to negotiate (Bont \& Heinimann 2012). Cable yarder set ups offer all the conditions that are ideal for automation: a fixed pre-defined route; a repetitive travelling cycle; a relatively short distance that facilitates remote exchanging of large volumes of data (plus, the possibility to use the skyline as a conductor for transmitting all kinds of waves).

For those reasons, experimentation with yarder automation began very early and has been generally successful (Yamada 1990, Numata et al. 1995). Today, most European based yarder manufacturers offer automated work options for their machines (Erber \& Spinelli 2020). Therefore, while colleagues in the ground-based transportation sector grapple with the technical challenges of developing autonomous versions of their products, the yarding sector is already there and could be used for testing the benefits of automation, under real work conditions. One may expect many benefits from automation, including increased productivity, better management of human resources and improved operator safety and comfort.

The goal of this study is to determine if the automation of carriage travel in a commercial yarding operation has any effect on work productivity and organization. The null hypothesis is that productivity is the same under manual and automated operation (in which case one may look for other justifications to the implementation of automatic operation).

\section{Materials and methods}

The study was conducted in a spruce-dominated (Picea abies Karst.) stand in the Eastern Italian Alps, near Arta Terme in the Province of Udine. The stand measured 14.7 ha and grew at a mean elevation of $650 \mathrm{~m}$ asl. The forest consisted of an upper storey of large mature and over-mature spruce trees intermixed with sporadic fir (Abies alba L.), and a lower storey of dominated hardwoods (Ostrya carpinifolia Scop. and Castanea sativa L.) and sparse fir regeneration. The prescribed treatment was the complete removal of all mature and over-mature spruce trees, and of the mature hardwoods, while leaving all healthy young and mature fir. Total removal was estimated at $1475 \mathrm{~m}^{3}$ or $100 \mathrm{~m}^{3} \mathrm{ha}^{-1}$ (all volumes are over bark).

Trees were felled by chainsaw and then yarded downhill to the forest road located on the lower border of the compartment. Trees and tree sections would then be yarded downhill, where they would be processed into logs. In particular, two lines were set up, with a total length (spar to spar) of $350 \mathrm{~m}$ and 280 $\mathrm{m}$, respectively (Figure 1). The longer line was installed first and consisted of two spans, with a support set $120 \mathrm{~m}$ uphill from the landing. The second and shorter line was single-span. The two lines led to two separate landing pads, built in the immediate proximity of the mentioned valley road.

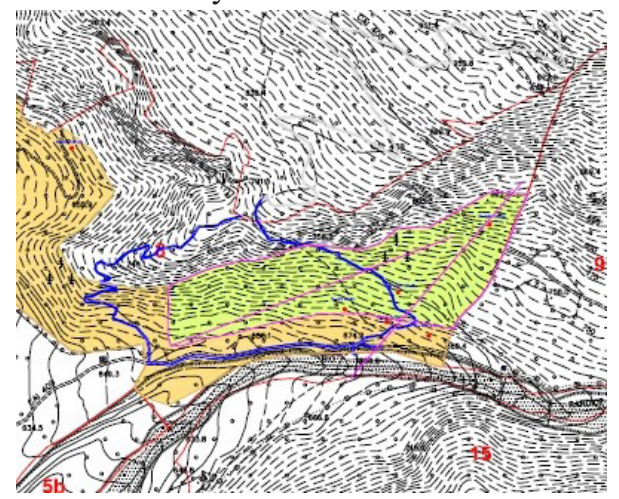

Figure 1 Map of the experimental site and the two cable lines 
The yarder was a Valentini V850 M3 trailer-mounted tower model. The machine had a maximum skyline capacity of 850 $\mathrm{m}$ (22 $\mathrm{mm}$ cable) and was equipped with three hydraulically-powered winches for the skyline, the mainline and the haulback line. The mainline and haulback drums were fitted with a hydraulic interlock and carried $900 \mathrm{~m}$ of $12 \mathrm{~mm}$ cable and $1800 \mathrm{~m}$ of $11 \mathrm{~mm}$ cable, respectively. Five additional drums were available for the guylines (4) and the strawline (1). The tower could telescope up to 12.5 $\mathrm{m}$, and during the study was fully extended. The machine was fitted with its own $175 \mathrm{~kW}$ diesel engine. The yarder was equipped with a Hochleitner Bergwald 4000 3-t capacity selfclamping mechanical slack-pulling carriage, which is standard on this yarder model. In both cases the tailhold was a large sound spruce tree. The rigging was a classic three-line allterrain configuration, with a standing skyline to support the carriage and the mainline and haulback lines to move it back and forth between the loading and unloading sites. Once the carriage was clamped, the haulback line pulled slack off the mainline, which also served as the liftline.

The crew was composed by four operators: two at the loading site for hooking trees to the mainline and eventually crosscutting overlarge specimen with a chainsaw, and two at the unloading site for unhooking incoming loads, processing trees with a chainsaw and stacking logs with a 12-t Hitachi Zaxis 110 excavator-based loader. However, when working at line 1, one of the operators would occasionally leave so that the crew was reduced to three. Interface (HMI)
Conversely, during work at line 2, a fifth worker joined the unloading crew and the machine was always manned by five operators. All operators were experienced and possessed the necessary professional qualifications.

The yarder was equipped with the dedicated Valentini electronic radio-control system with automatic path programming, consisting of two receivers installed on the yarder and two transmitters. One transmitter was for the breaker-out at the loading station and the other for the winch operator at the unloading station, whereby the radio transceivers were on the carriage (for long distance transmission) and on the Human Machine Interface (HMI) display designed for adjusting all work settings. All these devices would communicate directly with the on-board computer (OBC) electronic system. Path programming is an integral component of this system, and it allows setting carriage stops, carriage speed and carriage acceleration and deceleration ramps at specific points along the path. All points and parameters are clearly displayed on the HMI, together with other machine data and diagnostics (Figure 2). That way, the carriage moves automatically and at the desired speed along the skyline, allowing the operators to tend other business instead of manually

\section{Automatic System Settings}

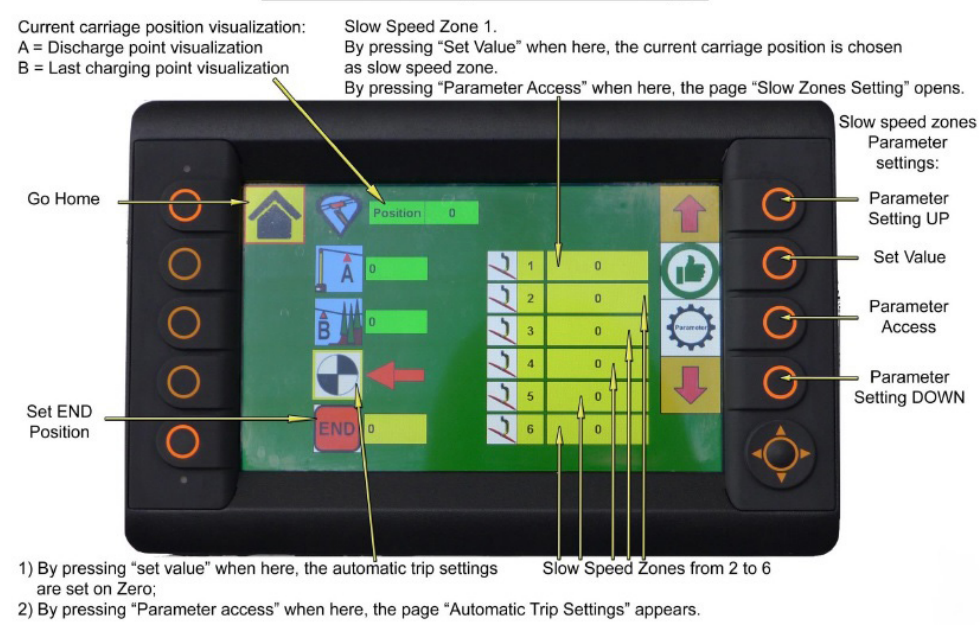

Figure 2 The path-programming interface on the Valentini Human Machine 
controlling carriage operation all along. When the carriage reaches its programmed stop, then it waits until taken over by the operator on site, through one of the two remote controls.

For the purpose of this study, the yarder was run alternately under the path-programming and the manual-control modes (henceforth: automated and manual, respectively).

The test covered a total of 8 days, 4 in February 2018 and 4 in March of the same year. The split was operated in order to sample both lines and extend the range of conditions for the comparative trial. Treatments were swapped every workday in order to guarantee even work conditions, and to allow operators to get accustomed with the new operating mode. The treatment for the first day was selected randomly, so as to avoid that one treatment only sampled the morning and the other the afternoon. Overall, the study included 127 and 153 complete cycles for the manual and the automated treatment, respectively (Figure 3). Total test duration was 61 hours of worksite time, including delays. During this time, the yarder crew extracted $431 \mathrm{~m}^{3}$ of wood (over bark).

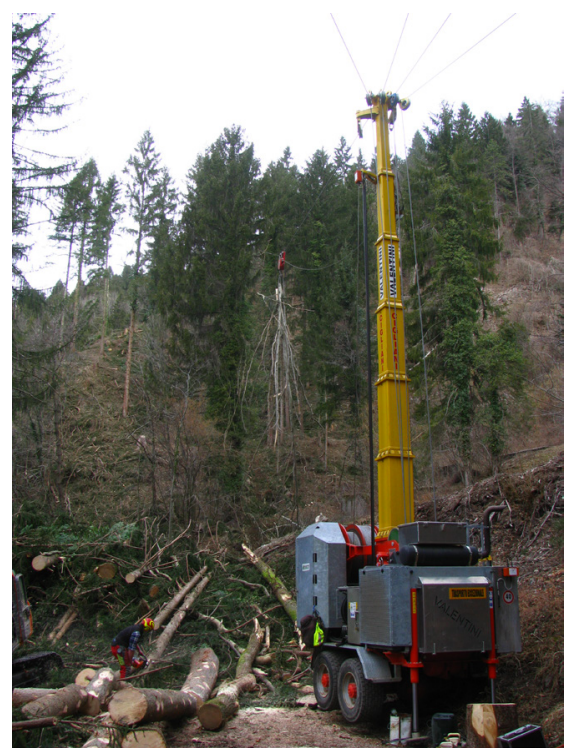

Figure 3 The tower yarder at work, during inhaul

\section{Measurements}

The study method was designed to include time consumption, extraction distance and load size. This was done individually for each cycle $(n=280)$. Fuel consumption was also recorded, although at daily intervals only $(\mathrm{n}=8)$.

A classic time-motion study was conducted at the cycle level. Time was recorded separately for the following time elements: unloaded carriage trip (outhaul); loading; travel loaded (inhaul); unloading; downtime - split into mechanical, operational and personnel delays.

Yarding distance - i.e., the distance between the loading and unloading sites - was measured with a Bushnell Yardage Pro 500 laser range finder. Mean lateral skidding distance was estimated by the operators at approximately 15 $\mathrm{m}$, and never exceed $40 \mathrm{~m}$.

Load size was obtained by determining the volume of all trees and tree sections in each load. Upon unloading, a researcher noted the species and the diameter at breast-height (DBH) of all whole trees. Whenever possible, total tree length was determined with a logger's tape. As a result, DBH-to-height curves were built for spruce $(\mathrm{n}=30)$ and hardwoods $(\mathrm{n}=$ 10). Later, $\mathrm{DBH}$ and height values were entered into the equations published by Tabacchi et al. (2011) for spruce and hornbeam, obtaining an estimate of stem volume over bark, to a minimum top diameter of $5 \mathrm{~cm}$. The volume over bark of tree sections was calculated after measuring the total length and the diameter at mid-length of each element.

Machine cost was calculated using the spreadsheet developed within the scope of European COST Action FP0902 (Ackerman et al. 2014). Main costing assumptions (investment cost, service life, insurance cost, fuel consumption and cost, maintenance cost etc.) were obtained directly from the machine owner and/or the manufacturer. Labour cost was set at $20 €$ per scheduled machine hour $(\mathrm{SMH})$, inclusive of indirect salary costs. 
Raw machine cost was increased by $25 \%$ to account for overhead costs (Hartsough 2003). Further detail on cost calculations is shown in Table 1. Please note that actual machine rates may differ from our calculated rates, based on local market conditions. While the automated system added 15,000 Euro to the purchase cost, this equated to $3 €$ per hour, or $1.5 \%$ of total.

Table 1 Cost estimates for the two treatments

\begin{tabular}{llrr}
\hline Operation & Type & Manual & Automated \\
\hline Investment & $€$ & 365,000 & 380,000 \\
Resale & $€$ & 109,500 & 114,000 \\
Service life & Years & 8 & 8 \\
Utilization & $\mathrm{h}_{\text {year }}{ }^{-1}$ & 1,000 & 1,000 \\
Interest rate & $\%$ & 4 & 4 \\
Depreciation & $€$ year $^{-1}$ & 31,950 & 33,250 \\
Interests & $€$ year $^{-1}$ & 10,100 & 10,550 \\
Insurance & $€$ year $^{-1}$ & 2,500 & 2,500 \\
Diesel & $€$ year $^{-1}$ & 15,600 & 15,600 \\
Lube & $€$ year & & \\
Repairs & $€$ year $^{-1}$ & 2,350 & 2,350 \\
Total & $€ \mathrm{~h}^{-1}$ & 78,000 & 16,600 \\
Crew & $\mathrm{n}$. & 4 & 81 \\
Labour & $€ \mathrm{~h}^{-1}$ & 80 & 4 \\
Overheads & $€ \mathrm{~h}^{-1}$ & 40 & 80 \\
Total rate & $€ \mathrm{~h}^{-1}$ & 198 & 201 \\
\hline
\end{tabular}

Notes: The estimate refers to the complete tower yarder, the excavator and a crew of 4 . Costing assumptions were provided by the machine owner. Hours are scheduled machine hours $(\mathrm{SMH})$, including delays.

\section{Data analysis}

Data were analyzed statistically using the SAS Statview software (SAS 1999). The individual work cycle (turn) was assumed as the observational unit (repetition). The significance of the differences between mean values for the two treatments and the two lines was tested through the analysis of variance (AnOVa) for outhaul and inhaul cycle time and speed, since these data satisfied the parametric assumptions. Differences between groups were then attributed using the Tukey-Kramer test. On the other hand, the distribution of loading and unloading cycle time violated the normality assumption and the data was analyzed using the Kruskal-Wallis non-parametric test. Differences between groups were then attributed through Scheffe's test, which is robust to violation of the parametric assumptions. Multiple linear regression analysis allowed testing the relationship between the duration of work tasks (cycle elements) and such influencing factors as extraction distance, load size, treatment, Line etc. The analysis of the residuals allowed excluding serial correlation potentially deriving from gross measurement errors. In all analyses, the elected significance level was $\alpha<0.05$.

\section{Results}

Mean payload was approximately $1.5 \mathrm{~m}^{3}$, with no significant differences between treatments or lines (Table 2). Maximum payload reached as high as $5 \mathrm{~m}^{3}$ when handling a large overmature spruce tree with a DBH of $63 \mathrm{~cm}$, but that was an exceptional occurrence. Perhaps a better representation of a sustainable optimum payload could be offered by the upper quartile, estimated at approximately $2 \mathrm{~m}^{3}$ per turn. The number of pieces per load was 1.9 for Line 1 and 1.4 for Line 2, with no significant differences between the manual and the automated treatment. Outhaul and inhaul time were significantly longer for the automated treatment on Line 1 ( $p<0.0001$, for both), which was easily explained by the significantly longer extraction distance recorded there $(\mathrm{p}=0.0121)$. Inhaul time was also shortest for the automated treatment, on Line $2(\mathrm{p}<0.0001)$.

However, a changing extraction distance accounted for these differences, at least in part. Carriage speed was a better indicator because it integrated distance and thus balanced off most of its effects. Outhaul speed was slowest under the automatic treatment, but only on Line 2. In contrast, inhaul speed was always faster ( 5 to $20 \%$ ) for the automated treatment, regardless of Line. Loading time was significantly longer for the manual treatment on Line $2(p=0.0002)$, while no significant differences were 
Table 2 Main results of the time study

\begin{tabular}{llcccccccc}
\hline & & \multicolumn{4}{c}{ Line 1 } & \multicolumn{4}{c}{ Line 2 } \\
\hline Treatment & U.M. & $\begin{array}{c}\text { Manual } \\
(\mathrm{n}=78) \\
\text { Mean }\end{array}$ & \multicolumn{3}{c}{$\begin{array}{c}\text { Auto } \\
(\mathrm{n}=72)\end{array}$} & $\begin{array}{c}\text { Manual } \\
(\mathrm{n}=49)\end{array}$ & \multicolumn{3}{c}{$\begin{array}{c}\text { Auto } \\
(\mathrm{n}=81)\end{array}$} \\
\hline Inhaul distance & $\mathrm{m}$ & $158^{\mathrm{ab}}$ & 64 & $242^{\mathrm{c}}$ & 55 & $185^{\mathrm{b}}$ & 50 & $137^{\mathrm{a}}$ & 58 \\
Load & pieces & $1.9^{\mathrm{a}}$ & 0.9 & $1.9^{\mathrm{a}}$ & 0.9 & $1.4^{\mathrm{b}}$ & 0.6 & $1.4^{\mathrm{b}}$ & 0.8 \\
Load & $\mathrm{m}^{3}$ & $1.53^{\mathrm{a}}$ & 0.57 & $1.41^{\mathrm{a}}$ & 0.62 & $1.58^{\mathrm{a}}$ & 0.74 & $1.65^{\mathrm{a}}$ & 0.92 \\
Outhaul & $\mathrm{S}$ & $60^{\mathrm{a}}$ & 31 & $89^{\mathrm{b}}$ & 18 & $63^{\mathrm{a}}$ & 18 & $60^{\mathrm{a}}$ & 28 \\
Loading & $\mathrm{S}$ & $271^{\mathrm{a}}$ & 148 & $328^{\mathrm{a}}$ & 170 & $452^{\mathrm{b}}$ & 438 & $264^{\mathrm{a}}$ & 48 \\
Inhaul & $\mathrm{S}$ & $112^{\mathrm{a}}$ & 47 & $137^{\mathrm{b}}$ & 26 & $117^{\mathrm{a}}$ & 42 & $83^{\mathrm{c}}$ & 35 \\
Unloading & $\mathrm{S}$ & $90^{\mathrm{a}}$ & 35 & $99^{\mathrm{a}}$ & 45 & $78^{\mathrm{a}}$ & 46 & $85^{\mathrm{a}}$ & 43 \\
Outhaul speed & $\mathrm{m} \mathrm{s}^{-1}$ & $2.97^{\mathrm{a}}$ & 1.06 & $2.76^{\mathrm{b}}$ & 0.58 & $2.97^{\mathrm{ab}}$ & 0.60 & $2.41^{\mathrm{b}}$ & 0.70 \\
Inhaul speed & $\mathrm{m} \mathrm{s}^{-1}$ & $1.49^{\mathrm{a}}$ & 0.51 & $1.80^{\mathrm{a}}$ & 0.41 & $1.65^{\mathrm{a}}$ & 0.34 & $1.74^{\mathrm{b}}$ & 0.49 \\
Crew & $\mathrm{n}^{\circ}$ & $3.5^{\mathrm{a}}$ & 0.5 & $3.5^{\mathrm{a}}$ & 0.6 & $5.0^{\mathrm{b}}$ & 0.0 & $5.0^{\mathrm{b}}$ & 0.0 \\
Productivity & $\mathrm{m}^{3} \mathrm{PMH}^{-1}$ & $11.3^{\mathrm{ab}}$ & 5.2 & $8.2^{\mathrm{c}}$ & 3.8 & $9.3^{\mathrm{bc}}$ & 5.0 & $13.3^{\mathrm{a}}$ & 8.1 \\
\hline
\end{tabular}

Notes: $\mathrm{SD}=$ Standard deviation; $\mathrm{m}^{3}=$ volume over bark; $\mathrm{PMH}=$ Productive machine hours, excluding delays; Values in the same row marked with a different superscript letter are significantly different at the $5 \%$ probability level. Differences were tested using a general linear model and the post-hoc Tukey-Kramer test.

found between treatments or lines for un- $90 \%$ of the total Sum of Squares (Table 3). loading time, which was always very short (one minute to one minute and a half).

The overall incidence of delays was quite small (11\% of total) as the yarder team met with very few unplanned interruptions of their work routine: on the other hand the relatively long duration of the study (8 full working days) may support cautious inclusion of this figure in further calculations. In any case, the erratic character of delay events made it impossible to detect significant differences between the treatments on test, and in the absence of treatment-specific occurrences (e.g., failure of the path-programming software) it was decided that all following projections of delay time would be based on the overall average delay time for the whole study without any differences between treatments.

Productivity varied between 8 and $13 \mathrm{~m}^{3} \mathrm{PMH}^{-1}$, and was higher for the manual treatment on Line 1 and for the automated treatment on Line 2.

The analysis of variance indicated the prevalent role of random variability which represented between 70 and

Table 3 Analysis of variance of the main dependent variables

\begin{tabular}{|c|c|c|c|c|c|c|}
\hline \multirow{3}{*}{$\begin{array}{l}\text { Dependent } \\
\text { Distance } \\
\mathrm{m}\end{array}$} & \multicolumn{2}{|c|}{ Independent DF } & \multirow{2}{*}{$\begin{array}{r}\mathrm{SS} \\
21350\end{array}$} & \multicolumn{2}{|c|}{$\eta^{2} \mathrm{~F}$-Value } & \multirow{2}{*}{$\frac{\text { P-Value }}{0.0121}$} \\
\hline & Treatment & 1 & & 1.6 & 6.39 & \\
\hline & Line & 1 & 101161 & 7.6 & 30.25 & $<0.0001$ \\
\hline & Inte & 1 & 289877 & 21.7 & 86.69 & $<0.000$ \\
\hline & Res & 276 & 922888 & 69.1 & & \\
\hline \multirow{4}{*}{$\begin{array}{l}\text { Outhaul } \\
\text { time } \\
\mathrm{s}\end{array}$} & Treatment & 1 & 11512 & 5.4 & 18.20 & $<0.000$ \\
\hline & Lir & 1 & 10434 & 4.9 & 16.49 & 0 \\
\hline & & 1 & 17707 & 8.3 & 27.99 & 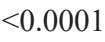 \\
\hline & & 276 & 74524 & 81.5 & & \\
\hline \multirow{4}{*}{$\begin{array}{l}\text { Inhaul time } \\
\mathrm{s}\end{array}$} & & 1 & 1735 & 0.3 & 1.19 & 0.27 \\
\hline & Lit & 1 & 39854 & 7.9 & 27.37 & $<0$ \\
\hline & & 1 & 58735 & 11.7 & 40.34 & $<0.00$ \\
\hline & & 276 & 401833 & 80.0 & & \\
\hline \multirow{4}{*}{$\begin{array}{l}\text { Outhaul } \\
\text { speed } \\
\mathrm{m} \mathrm{s}^{-1}\end{array}$} & Tre & 1 & 12 & 6.8 & 21.30 & $<0.000$ \\
\hline & & 1 & 4 & 2.0 & 6.21 & 0.013 \\
\hline & & 1 & 6 & 3.1 & 9.70 & 0.002 \\
\hline & & 6 & 158 & 88.1 & & \\
\hline \multirow{3}{*}{$\begin{array}{l}\text { Inhaul } \\
\text { speed } \\
\mathrm{m} \mathrm{s}^{-1}\end{array}$} & Treatment & 1 & 2 & 4.1 & 12.33 & 0.000 \\
\hline & & 1 & 3 & 4.7 & 14.30 & 0.000 \\
\hline & $\mathrm{Re}$ & & 55 & 91.2 & & \\
\hline \multirow{4}{*}{$\begin{array}{l}\text { Productivity } \\
\mathrm{m}^{3} \mathrm{PMH}^{-1}\end{array}$} & $y \operatorname{Tre}$ & 1 & 224 & 2.1 & 6.97 & 0.008 \\
\hline & Dis & 1 & 1198 & 11.5 & 37.29 & $<0.000$ \\
\hline & & 1 & 163 & 1.6 & 5.08 & 0.025 \\
\hline & Residual & 276 & 8867 & 84.8 & & \\
\hline
\end{tabular}

Notes: PMH $=$ Productive machine hours, excluding delays; $\mathrm{DF}=$ Degrees of freedom; SS = Sum of squares; $\eta^{2}=$ strenght of effect, i.e., the ratio of SS for the effect in question as a percent of total SS; No interaction factor effect was reported for Inhaul Speed, since the interaction factor had no significant effect 
Nevertheless, the effects of both treatment and line did emerge as significant, occasionally as a combined effect (i.e., with one treatment performing better on one Line and worse on the other).

Table 4 Results of the regression analysis for the following dependent variables: outhaul time and speed, inhaul time and speed, net productivity (excluding delays)

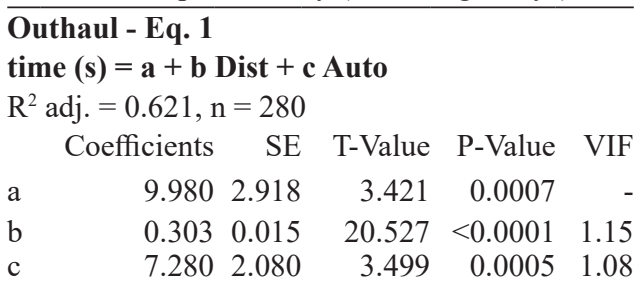

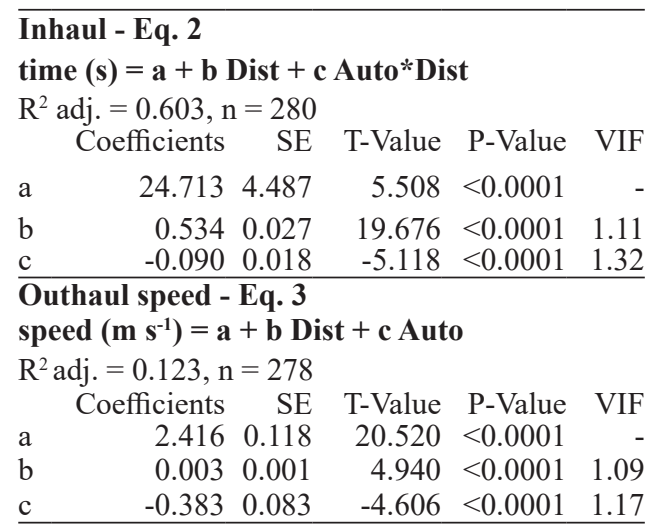

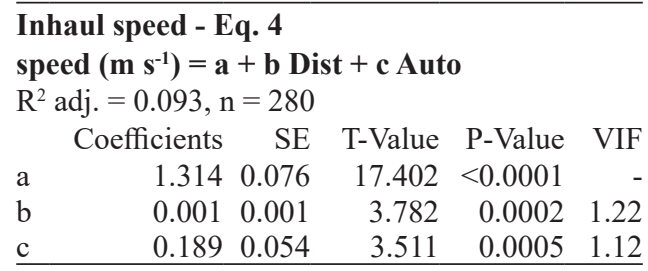

Net productivity - Eq. 5 $\mathbf{m}^{3} \mathbf{P M H}^{-1}=\mathbf{a}+$ b Dist + c Auto + d Auto*Dist $\mathrm{R}^{2}$ adj. $=0.163, \mathrm{n}=280$

\begin{tabular}{lrrrrr} 
& Coefficients & SE & T-Value & P-Value & VIF \\
a & 13.855 & 1.494 & 9.276 & $<0.0001$ & - \\
$\mathrm{b}$ & -0.020 & 0.008 & -2.371 & 0.0184 & 1.03 \\
$\mathrm{c}$ & 5.069 & 1.920 & 2.640 & 0.0088 & 1.23 \\
$\mathrm{~d}$ & -0.020 & 0.010 & -2.253 & 0.0251 & 1.16 \\
\hline
\end{tabular}

Notes: $\mathrm{R}^{2}$ adj. $=$ Adjusted $\mathrm{R}^{2} ; \mathrm{SE}=$ Standard Error; Dist $=$ extraction distance in $\mathrm{m}$; Auto $=$ Indicator variable for the automated treatment, Auto $=1=$ Automated, Auto $=0=$ Manual; VIF = Variance Inflation Factor.
Regression analysis found logical, strong $\left(\mathrm{R}^{2}>0.6\right)$ and significant $(\mathrm{p}<0.001)$ relationships between travel time, extraction distance and treatment (Table 4). Travel time increased with travel distance as expected, and was shorter for outhaul under the manual treatment (Eq. 1 and Figure 4) and for inhaul under the automated treatment (Eq. 2 and Figure 4). This was confirmed by the regressions for travel speed, which indicated how outhaul speed was faster for the manual treatment (Eq. 3), and inhaul speed for the automated one (Eq. 4). These equations also indicated that mean travel speed increased with distance: as the trip got longer, the incidence of the fixed acceleration and deceleration ramps at the beginning and the end of the trip would get smaller. It is worth noting that Eq. 2 does point at a faster inhaul speed under the automated treatment, as expressed by the distance * treatment interaction variable: on the contrary, Eq. 1 indicates that the longer duration of the outhaul trip under the automated treatment is independent of distance and therefore can be construed as a fixed delay rather than a proportional one (e.g., a lower speed). This may point at a conservative setting of the acceleration ramps during path programming, which may have caused the carriage to gain cruise speed later under the automated treatment than under the manual one. Load size had no effect on travel time or speed, typically an indication that the system was operating well within its capability.

Finally, Eq. 5 (Table 4) indicates that productivity was higher under the automated treatment, but this margin would decrease with distance. This can be explained by the speed advantage gained by the automated treatment in the inhaul being smaller than the speed advantage gained under the manual treatment in the outhaul: therefore the manual treatment would tend to catch up as distance increased. However, this equation has a very weak explanatory power and it may be safer to use it as a general indication of system behaviour, rather than for predictive purposes. 

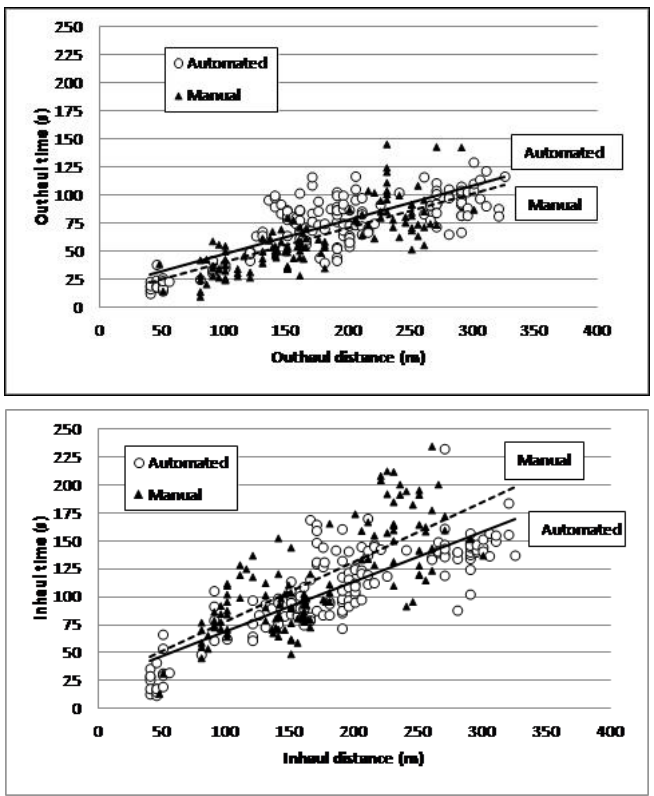

Figure 4 Point scatter and regression graph for outhaul (top) and inhaul time (bottom)

The cost effectiveness of the two treatments was evaluated by estimating outhaul and inhaul time based on equations 1 and 2 which are the only ones with a good explanatory power, then adding loading and unloading time as the means calculated across the study, since the study did not detect any significant differences between treatments for these work tasks. The resulting cycle time was inflated by $12 \%$ to account for delay time based on the overall study data. Productivity was estimated for a mean load size equal to $1.54 \mathrm{~m}^{3}$, which was the grand mean extracted from the complete dataset and was adopted for both treatments due to the absence of any significant difference between them when it came to load size. Estimated productivity was used to divide the hourly cost reported in Table 1, thus obtaining yarding and processing cost. This ranged between 19 and $30 € \mathrm{~m}^{-3}$, and was lower for the automated treatment when distance exceeded $200 \mathrm{~m}$ (Figure 5). In any case, extraction cost differences were modest, and in the vicinity of $2 \%$.

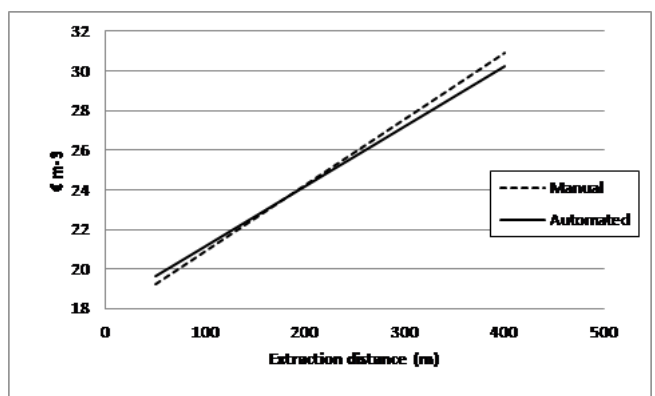

Figure 5 Relationship between extraction cost, extraction distance and automation level

Note: Graphs calculated on the basis of regression equations 1 and 2 (Table 4), for the mean loading and unloading time (404 s) and a mean load size of $1.54 \mathrm{~m}^{3}$. Net time was inflated by a $12 \%$ Delay Factor to obtain scheduled time. Machine cost was obtained from Table 1.

\section{Discussion}

The general figures reported above are corroborated by several published studies conducted under similar conditions, confirming the selected operation as representative of a type that is relatively common in the Alpine region. The productivity figures reported in this study are firmly within the limits spanned by recent studies carried out by the same Authors, with same methods and in the same region. Those studies reported average productivity figures of $7.6 \mathrm{~m}^{3} \mathrm{SMH}^{-1}$ on a distance of 700 $\mathrm{m}$, or between $8.5 \mathrm{~m}^{3} \mathrm{SMH}^{-1}$ and $12.1 \mathrm{~m}^{3} \mathrm{SMH}^{-1}$ on a $230 \mathrm{~m}$ distance (Spinelli et al. 2015). All for the same machine type and size, engaged with yarding spruce trees (or logs) downhill on a three cable configuration set-up.

Load size seemed to have no effect on travel time or speed: given that load size variability was large enough (from 0.3 to $5.5 \mathrm{~m}^{3}$ ), this may indicate that most of the time the machine was working well within the limits of its capacity (Spinelli et al. 2017). Besides, power is less of a limit in downhill yarding, when gravity aids with taking the load to the landing and the winch has rather to slow the load down than pull it up. Power may be a limit that could show when breaking out the load, not when the 
load is already under the skyline. So, the effect of load size was likely easier to emerge in the loading phase, but the inability to measure a lateral distance led to a confounding effect that must have masked the role of load size. In that regard, one may suspect that the significantly longer loading time recorded for Line 2 under the manual treatment may have been related to a significantly longer extraction distance, but in the absence of hard data that remains speculation.

As expected, travel time (outhaul and inhaul) increased with distance and was affected by treatment, according to a neat linear regression that explained over $60 \%$ of the variability in the data. Most previous studies report similar linear relationships, pointing at a constant travel speed (Spinelli et al. 2015, Spinelli et al. 2017). More interesting is how the models represent treatment effect, since automation leads to increased outhaul time and decreased inhaul time, all rest being equal. In that regard, the specific form of the two functions can be enlightening: the equation for outhaul time describes the time increase experienced when shifting to the automated treatment as a fixed effect, as it may arise from an overly long acceleration or deceleration ramp, or some form of reaction lag on the part of the command. On the other hand, the equation for inhaul time describes the time reduction derived from shifting to the automated treatment as an interaction effect, proportional to distance - hence a higher speed. This may indicate that automation has indeed the potential for increased travel speed, and that the contradictory result obtain for the outhaul is due to some interference, that may or may not be related to the treatment itself. When this effect is explored in terms of speed, similar results are obtained, although they are represented in terms of increasing and decreasing speed only because the type of relationship does not allow describing them in any other form. These functions show that speed increases with distance, possibly due to the momentum gained by the carriage as it travels, or - more likely - by the fact that the effect of any interruptions or reaction lag (discrete events) becomes diluted as distance increases and shows in the equation as an increase in overall speed, even if actual speed remained the same.

The relationship for productivity is too weak for extracting reliable predictions, but it offers confirmation of these general trends. Similarly, the cost estimates presented in Figure 5 must be taken with much caution, since treatment effect was confounded by background noise that made it difficult to determine with much accuracy the financial benefit derived from path programming. Nevertheless, the study shows that there is a benefit and that this benefit is not very large, at least under the conditions represented by this study. The fact that this study was capable of establishing such advantage is the result of its controlled experimental design, which dampened a very large background noise and allowed tuning in on a relatively small factor effect. This is a rare quality for yarder productivity studies, which generally have observational character (Lindroos \& Cavalli 2015). Even so, this study has important limitations. In particular, it offered only an approximate estimate of delay time, and could not indicate whether there would be any difference between treatments when it came to downtime, while it would be legitimate to ask if the additional complexity of the automation software may cause an increase of malfunction events or - conversely - if operational downtime would be reduced through automation. Furthermore, the study was based on one machine and one crew, only.

Another limitation is that the automation settings, such as carriage speed, are programmed by the operator. This study was not able to assess if these settings were adjusted in the most efficient way for the specific conditions. It is certain that all the operators chosen for the study were competent and experienced professionals and were well acquainted with the specific system they were using. In our opinion, the most severe 
limitation of this study is the specific operation under which it was used, which is likely the most common type in the Italian Alps (Spinelli et al. 2013), but perhaps not the best placed for reaping all the benefits automation may offer. This operation was semi-mechanized and labor-intensive, designed for the motormanual processing of incoming trees and the stacking of logs with a loader, for which tasks two or even three operators were assigned and available on site. As a consequence, one operator was always capable of keeping an eye on the carriage without excessive disruption, even when the system was run in the manual mode. At the same time, the high labour requirements of motor-manual processing made it difficult to reduce crew size even under the automated treatment, which denied the primary objective of yarder automation - i.e., the downsizing of large crews (Ito \& Uemura 2011). That is the same reason why early tests of remote-controlled carriages failed to substantiate any concrete benefits, while today we consider a remote control as an almost indispensable element for any modern yarder (Cristensen 1978). Theoretically a better comparison would have been one that matched the manual operation just described, with another operation where the two (or three) operators at the landing and the loader that went along had been replaced by a single operator placed on a processor and running the yarder under automated control (Spinelli et al. 2017). That amounts to say that automation works best when it is part of a general system shift, and not just one isolated incremental change. On the other hand, while a bolder effort to innovation is likely necessary to notice a meaningful reduction of yarding cost, one should not underestimate the effect of automation on operator mental workload: even if path programming did not significantly boost productivity, it is most likely that it eased the yarder control task, relieving part of the burden imposed on the winch operator. That may reflect on long-term productivity and operator wellbeing and should be the specific subject of future research.

\section{Acknowledgements}

This project has received funding from the Bio Based Industries Joint Undertaking under the European Union's Horizon 2020 research and innovation programme under grant agreement No 720757 - Tech4Effect. The authors also acknowledge the support received from Dr. G. Aminti and Dr. F. de Francesco (CNR IBE) with field data collection and from ConAIBo with the organization of the trial.

\section{References}

Acemoglu D., Restrepo P., 2017. Robots and Jobs: Evidence from US Labor Markets (March 17, 2017). MIT Department of Economics Working Paper No. 17-04. 2017. https://ssrn.com/abstract=2940245. Accessed: 02.2020.

Ackerman P., Belbo H., Eliasson L., De Jong A., Lazdins A., Lyons J., 2014. The COST model for calculation of forest operations costs. International Journal of Forest Engineering 25: 75-81.

Billingsley J., Visala A., Dunn M., 2008. Robotics in Agriculture and Forestry. In: Siciliano B., Khatib O. (eds) Springer Handbook of Robotics. Springer, Berlin, Heidelberg. DOI: 10.1007/978-3-540-30301-5_47.

Bont L., Heinimann H., 2012. Optimum geometric layout of a single cable road. European Journal of Forest Research 131: 1439-1448.

Christensen J., 1978. Description of remote control cable yarding systems and an evaluation of the Forestral Remote Control Grapple Yarding System". Graduate Student Theses, Dissertations, \& Professional Papers. University of Montana, Missoula, MT, USA. 70 p. https://scholarworks.umt.edu/etd/2008. Accessed: 02.2020 .

Cottrel N., Barton B., 2013. The role of automation in reducing stress and negative affect while driving. Theoretical Issues in Ergonomics Science 14 (1): 5368. DOI: 10.1080/146453 6X.2011.573011

Erber G., Spinelli R., 2020. Timber extraction by cable yarding on flat and wet terrain: a survey of cable yarder manufacturer's experience. Silva Fennica 54(2). DOI: $10.14214 /$ sf.10211

Grzywiński W., Hołota R., 2006. Subjective assessment of the fatigue of forest workers based on Japanese questionnaire. Acta Scientiarum Polonorum Silvarum Colendarum Ratio et Industria Lignaria 5(1): 27-37.

Guimier D.Y. 1991. Canadian perspective on mechanized harvesting development. In: Mechanized harvesting: The future is here. Conference proceedings, Department 
of Forest Engineering, Oregon State University, Corvallis, OR, USA, p. 1-6.

Hartsough B., 2003. Economics of harvesting to maintain high structural diversity and resulting damage to residual trees. Western Journal of Applied Forestry 18: 133-142.

Heinimann R., 2007. Forest operations engineering and management: the ways behind and ahead of a scientific discipline. Croatian Journal of Forest Engineering 28: 107-121.

Hellström T., Lärkeryd P., Nordfjell T., Ringdahl O., 2009. Autonomous Forest vehicles: historic, envisioned, and state-of-the-art. International Journal of Forest Engineering 20: 31-38. DOI: 10.1080/14942119.2009.10702573.

Hellström T., Johansson T., Ringdahl O., Georgsson F., Prorok K., Sandström U., 2005. Development of an autonomous path tracking forest machine, International Conference on. Field Service Robotics, Port Douglas. Australia.

Ito T., Uemura T., 2011. Automatic control for a selfpropelled carriage to enable one-man cable yarding. Proceedings of FORMEC 2011, Graz, Austria, 11p.

Lindroos O., Cavalli R., 2016. Cable yarding productivity models: a systematic review over the period 2000-2011. International Journal of Forest Engineering 27: 79-94.

Löfgren B. 2009. Kinematic control of redundant knuckle boom with automatic pathfollowing functions. Dissertation, Royal Institute of Technology, Stockholm, Sweden.

Manner J., Gelin O., Mörk A., Englund M., 2017. Forwarder crane's boom tip control system and beginner-level operators. Silva Fennica 51(2). DOI: 10.14214/sf.1717.

Manninen M., Halme A., Myllylä R., 1984. An aimable laser time-of-flight range finder for rapid scene description, 7th Annual Conference of the British Robotics Association, Cambridge, UK.

Milliken P., Lamborn D., Keast A., 2015. Concept design for teleoperation of a John Deere 909 Feller Buncher. FFR Report No. H024, Rotorua, New Zealand, 16 p.

Mousazadeh H., 2013. A technical review on navigation systems of agricultural autonomous off-road vehicles. Journal of Terramechanics 50: 211-232.

Müller F., Jaeger D., Hanewinkel M., 2019. Digitization in wood supply - A review on how Industry 4.0 will change the forest value chain. Computers and Electronics in Agriculture 162: 206-218. DOI: 10.1016/j.compag.2019.04.002.
Numata K., Kanzaki K., Suzuki Y., Chu D., 1995. Application of automatic cable system to forest environment observation - Positioning precision of carriage and gondola with instrument units. Transaction of the Japanese Forestry Society 106: 545-548 [in Japanese].

Parker R., Bayne K., Clinton P., 2016. Robotics in Forestry. New Zealand Journal of Forestry 60: 8-14.

Prasad-Pant L., Hambly-Odame H., 2017. Broadband for a sustainable digital future of rural communities: A reflexive interactive assessment. Journal or Rural Studies 54: 435-450. DOI: 10.1016/j.jrurstud.2016.09.003.

Ringdahl O., Hellström T., Lindroos O., 2012. Potentials of possible machine systems for directly loading logs in cut-to-length harvesting. Canadian Journal of Forest Research 42: 970-985.

Scania, 2020. The fully autonomus Scania AXL. Scania Great Britain. Accessed April 26, 2020. https://www. scania.com/uk/en/home/experience-scania/features/axl. html. Accessed: 02.2020.

Spinelli R., Magagnotti N., Labelle E., 2020. The effect of new silvicultural trends on mental workload of harvester operators. Croatian Journal of Forest Engineering. 41 (2): 14 p. DOI: $10.5552 /$ crojfe.2020.747.

Spinelli R., Marchi E., Visser R., Harrill H., Gallo R., Cambi M., Neri F., Lombardini C., Magagnotti N., 2017. The effect of carriage type on yarding productivity and cost, International Journal of Forest Engineering 28: 3441. DOI: $10.1080 / 14942119.2016 .1267970$.

Spinelli R., Magagnotti N., Visser R., 2015. Productivity models for cable yarding in Alpine forests. European Journal of Forest Engineering 1: 9-14.

Spinelli R., Magagnotti N., Facchinetti D., 2013. A survey of logging enterprises in the Italian Alps: firm size and type, annual production, total workforce and machine fleet. International Journal of Forest Engineering 24: 109-120.

Tabacchi G., Di Cosmo L., Gasparini P., 2011. Aboveground tree volume and phytomass prediction equations for forest species in Italy. European Journal of Forest Research 130: 911-934.

Thor M., 2014. Prospects and Challenges for Forest Harvesting technologies in Europe. Proceedings of the 5th Forest Engineering Conference, 23-25/09/2014, Gerardmere, France. http://fec2014.fcba.fr/wp-content/ uploads/sites/4/2014/11/k1_magnusthor_2014-09.pdf. Accessed: 02.2020.

Yamada S., 1990. A full-automatic yarder system equipped with electronic devices. Journal of the Forest Mechanization Society 440: 23-28. [In Japanese] 